\title{
Possible predictors of temporomandibular disorders
}

\author{
What are the possible predictors of signs and symptoms of TMD in the \\ long-term?
}

\section{Carlsson GE, Egermark I, Magnusson T. Predictors of signs and symptoms of temporomandibular disorders: a 20-year follow-up study from childhood to adulthood. Acta Odontol Scand 2002; 60: 180-185}

Design Prospective cohort study of 402 randomly selected individuals aged 7-, 11- and 15-years' old at baseline. A total of 320 people completed a questionnaire after 20 years, with 100 patients who were aged 15 at initial examination being re-examined.

Outcome measures The questionnaire included questions about the presence of symptoms such as headaches, frequent stress or depression, previous trauma to the face and experience of temporomandibular disorders (TMD) during the 20 years of observation, and current demand for TMD treatment. The clinical examination was conducted to measure any TMD signs and symptoms including limitation to range of movement, temporomandibular joint (TMJ) sounds and pain. Tooth wear was recorded on a 5-point scale where 1 was no wear and 5 was wear of more than one-third of the clinical crown.

Results Data from the questionnaire and clinical examinations were combined and regression analysis performed. The presence of bruxism, oral parafunctions, TMJ clicking and deep bite at baseline were found to be significant predictors of TMD (see Table 1).

Conclusions Some signs and symptoms appear to be predictors of TMD. More research is needed, however, to determine if any of these parameters can be used to predict TMD in the long-term.

Table 1. Regression model with clinical dysfunction score as dependent variable.

\begin{tabular}{lccc}
\hline Independent variables (at start) & $\begin{array}{c}\text { Odds } \\
\text { ratio }\end{array}$ & $\begin{array}{c}95 \% \text { confidence } \\
\text { interval }\end{array}$ & $\begin{array}{c}\text { Adjusted } \\
\text { P-value }\end{array}$ \\
\hline $\begin{array}{l}\text { Bruxism } \\
\text { Bruxism with other oral }\end{array}$ & 5.3 & $1.1-25.0$ & 0.016 \\
parafunctions & 7.7 & $2.1-25.0$ & 0.003 \\
$\begin{array}{l}\text { Clinical TMJ clicking } \\
\text { Deep bite }\end{array}$ & 8.3 & $2.6-25.0$ & 0.002 \\
& 12.5 & $1.6-100.0$ & 0.025
\end{tabular}

TM], temporomandibular joint.

\section{Commentary}

The Gothenburg group have made great contributions to the knowledge of the epidemiology and prognosis of TMD. One of their longitudinal studies included a cohort of 402 randomly selected 7-, 11- and 15-year old subjects. Signs and symptoms of TMD in that cohort have previously been determined and described.

The ability to identify risk factors is of obvious importance in the management of disease. The aim of the present study was to determine risk factors for TMD. Twenty years on, remarkably, $94 \%$ of the cohort of 402 were traced and $85 \%$ of these participated in the study.

Variables from the follow-up questionnaire and clinical examination were chosen as dependent variables in logistic regression analyses, with independent variables selected from the baseline data. Moderate to severe tooth wear was the strongest predictor for TMJ clicking. Reported TMJ clicking at baseline was the only predictor for TMD symptoms without clicking 20 years later. Bruxism, oral parafunctions and deep overbite at baseline were found to be significant predictors of moderate to severe TMD symptoms detected by examination.

This study has identified some possible predictive factors that may be established by careful history and examination, but further studies are needed to establish their predictive value. The authors further emphasise that it is not possible to draw conclusions about whether such factors detected in childhood (parafunction, tooth wear, TMJ clicking and deep overbite) can predict manifest (patient awareness of) TMD.

\section{Practice point}

- Parafunction, tooth wear, TMJ clicking and deep overbite are possible predictors of TMD but their predictive value still requires further study.

\section{Robert G Jagger \\ Department of Restorative Dentistry, University of Wales College of Medicine, Cardiff, UK}

Evidence-Based Dentistry (2003) 4, 55 doi:10.1038/sj.ebd.6400213 